\title{
Social Media Marketing for User Engagement: Evidence from Bosnia and Herzegovina
}

\author{
Ensar Mekić \& Minela Zerdo-Puljić \\ International Burch University, Sarajevo, BOSNIA AND HERZEGOVINA \\ Faculty of Economics and Social Sciences
}

Received: 11 June 2021 • Accepted: 18 July 2021 • Published Online: 12 August 2021

\begin{abstract}
Internet enabled the emergence of social media platforms, opened new markets and changed the way businesses and organizations operate, communicate with their target audience, promote their activities and achievements. Non-profit organizations worldwide use social media platforms and strive to increase user engagement and the number of reactions to achieve their goals. Although in Bosnia and Herzegovina, non-profit organizations use social media platforms, there is no empirical evidence of their success in increasing user engagement and the number of reactions. This study investigates which social media factors have an influence on user engagement, particularly on the number of reactions on Facebook posts. The real data from the period of 15 months were collected from a Facebook business profile of a non-profit organization from Bosnia and Herzegovina. SPSS and Excel were used to analyze the data. According to the research results, the period of publishing and the number of photos have an effect on the number of reactions on Facebook posts, while the amount of text and the day of publishing do not have an effect on the number of reactions.
\end{abstract}

Keywords: social media, social media marketing, user engagement, the number of reactions on Facebook posts, Facebook.

\section{Introduction}

The number of Internet users is constantly growing, and it is not only because of the search engines but also because of the social media platforms which emerged from the Internet. There are 4.6 billion Internet users (Clement, 2020) and 3.6 billion of them use social media (Tatnkovska, 2020).

Social media platforms can also be seen as a market that connects the whole world. Withing few clicks marketers are able to reach their target audience and present them with new products and services, but customers can also be heard publicly through their comments and the number of reactions. The era of one-way communication where marketers were addressing their customers on traditional media ended. Now customers also create fan pages, share ideas and thoughts. Customers are able to support brands publicly and ruin them as well if they were dissatisfied with them. Regardless of disadvantages, the marketers use social media platforms to reach buyers (Gao et al., 2018), support brand evaluations (Naylor et al., 2012) and build closer connections with customers (Rapp et al., 2013). Social media advertising became the dominant

(C) Authors. Terms and conditions of Creative Commons Attribution 4.0 International (CC BY 4.0) apply. Correspondence: Ensar Mekić, International Burch University, Francuske Revolucije bb, 71210 Ilidža, Sarajevo, BOSNIA AND HERZEGOVINA. E-mail: ensar.mekic@ibu.edu.ba. 
tool to influence buying behavior (Chen \& Lin, 2019). Marketers strive to increase user engagement on social media because it may help them increase review, become industry leaders and game-changers.

User engagement is defined as "a desirable-even essential-human response to computer-mediated activities" (Laurel, 2013). User engagement is used as an indicator of the success of marketing efforts (Jaakonmäki et al., 2017). Social media platforms have their own analytics and track user engagement.

Facebook tracks engagement at the individual post level as well as the on-page level (Jessica, 2021). Facebook post engagement is measured through post shares, post reactions, post saves, post comments, post likes, post interactions, 3 -seconds video plays, photo views and link clicks (Post Engagement, n.d.).

The main objective of the study is to understand the effects of social media marketing on users' engagement, particularly on the number of reactions. The study aims to examine if the period of publishing, day of publishing, amount of text, the number of photos affect the number of reactions.

\section{Literature review}

\subsection{Social media marketing}

Despite the widespread understanding of social media sites, there are many definitions of social media marketing, but not a commonly accepted definition. Boyd and Ellison identified social media as:

web-based services that allow individuals to (1) construct a public or semipublic profile within a bounded system, (2) articulate a list of other users with whom they share a connection, and (3) view and traverse their list of connections and those made by others within the system (Groundswell, 2011, p. 211).

Kaplan and Haenlein defined social media as "a group of Internet-based applications that build on the ideological and technological foundations of Web 2.0 and that allow the creation and exchange of user-generated content" (2010).

Before the emergence of social networks, we know today, there were many attempts that had some of the characteristics of today's social networks. Open Diary was one of them. It resembled a social networking site - it gathered online diary writers in one place. Almost twenty years later, namely in 1979, Usenet was created by Tom Truscott and Jim Ellis from Duke University. It was "a worldwide discussion system that allowed Internet users to post public messages" (Kaplan \& Haenlein, 2010: 60).

The development of the Internet and the growing accessibility of high-speed Internet led to the development of social media. "One of the first social network sites was SixDegrees.com launched in 1997 by Andrew Weinreicht" (Barker et al., 2017). Weinreicht had the "six degrees of separation" theory on his mind - "the theory that any person on the planet can be connected to any other person on the planet through a chain of acquaintances that has no more than five intermediaries" (Arnold, 1989).

Adrian Scott wanted to help professionals make business contacts, so he created ryze.com in 2001. Unfortunately, it never grew into a big community (Barker et al., 2017). In 2003, Friendster was founded in California. It was meant to be a social networking site, but due to its unsuccess, it became a social gaming site in Malaysia and was eventually shut down. In 2002 LinkedIn was launched and Myspace started its music platform. LinkedIn now has almost 740 million members with over 55 million registered companies (Maddy, 2021). Facebook as we know 
it today was different when it was created in February 2004. It was called TheFacebook.com and it was created only to connect people with a harvard.edu email. Since then, Facebook became a global social networking site. It acquired Instagram, WhatsApp, and Oculus, and independently developed Facebook Messenger, Facebook Watch, and Facebook Portal. In 2005 YouTube was launched and a year later Tweeter was created. In 2007 David Karp founded Tumblr - a microblogging and social networking website. In 2010 Instagram was founded, and a year later, Google created Google+ and Snapchat. Ben Silbermann left Google and together with Evan Sharp, and Paul Sciarra founded Pinterest in 2010. Pinterest gathers those who love to share ideas and find inspiration for various interests and projects. In 2012 it became a social scrapbooking site. TikTok was released in 2016 and nowadays it is a fast-growing social media network whose content is created by its customers, mainly the young generation.

According to Statista (2020), Facebook is the most used social media platform, then WhatsApp, Facebook Messenger, and Instagram.

As it can be seen, social media network sites emerged one after another, and some were even inspired by one another. We cannot ignore the fact that social media sites have had a significant impact on the traditional marketing approach. Companies saw an opportunity to use social media sites to achieve their business and marketing goals, and this led to the emergence of social media marketing.

Social media marketing is a "connection between brands and consumers, [while] offering a personal channel and currency for user-centered networking and social interaction" (Chi, 2011).

It changed the way companies and clients communicate. In traditional marketing, marketers send messages to their potential clients, and the voice of clients is hardly heard. Social media marketing enabled two-way communication between marketers and clients. Now social media users, clients and potential clients can provide unique perspectives on what they consider personally meaningful (Di Gangi \& Wasko, 2016). Social media users, empowered by social media sites, take control of the marketing communication process by commenting, reviewing, creating content and collaborating with brands. This is beneficial for both, clients and companies, also because companies are able to get feedback on what they do well and what they do wrong, and thus improve their products and services and establish long-term relationships with their clients.

Thanks to social media sites, marketers can remotely perform their activities 24/7 and reach almost every part of the Earth. The pool of potential leads drastically increased, and costs decreased. Social media marketing activities cost much less than traditional marketing activities. Social media marketing is not limited to time, geographical space, and there is no need for a seller in an online shop and the shop is always open.

Besides the above-mentioned advantages of social media marketing, marketers are still struggling to engage the audience to be able to build long-term relationships with them. Corporations realized that without a correct plan and social media strategy they have no chance to stand out in the rapidly changing digital freedom (Sining \& Yanxia, 2012). They are striving to create effective inbound marketing strategies to be able to increase user engagement, achieve regular communication and eventually establish long-term relationships. Although there is no clear understanding of effective social media strategies, marketers heavily rely on social media analytics (SMA) to gain better insights into their target audience, their behaviors, wants and needs. „Social media analytics is concerned with developing and evaluating informatics tools and frameworks to collect, monitor, analyze, summarize, and visualize social media data, usually driven by specific requirements from a target application" (Zeng et al., 2010). E.g., Facebook analytics measures user engagement, impressions, reach, referral traffic, page likes, follows, ad metrics, video metrics, etc. Though SMA does not offer answers to all questions of marketers, it is 
still a marketing intelligence source that is beyond human capacities and a great asset to marketers.

\subsection{User engagement}

Thanks to the Internet, the way people perform their daily activities changed. Now we are able to buy goods and services from any part of the world from the comfort of our homes. Around 78 percent of Internet users are active on social media (Tatnkovska, 2020) and are creating content and engaging with brands daily.

Though marketers have access to a large number of users from all around the world, they are struggling to come up with a strategy that will help them engage their audience enough, so they become their loyal customers.

There is not a widely accepted definition of user engagement. Laurel defined user engagement as "a desirable-even essential-human response to computer-mediated activities" (2013). User engagement is also defined as "a user's response to an interaction that gains, maintains, and encourages their attention, particularly when they are intrinsically motivated" (Jacques, 1996: 103). O 'Brien and Cairns built upon Jacques` description of user engagement and said it is "a quality of user experience with technology" characterized by the perceived usability and aesthetic appeal of the system, focused attention, novelty, felt involvement, and endurability" (O’Brien \& Cairns, 2016: 3).

Richard Jacques wrote that engagement consisted of six attributes, each of which operated along a continuum: the degree of attention (divided or focused), motivation to continue the task, perceived control (presence or absence), needs satisfaction experienced by the user, the user's perception of time ("dragging on" or "flying by") and attitude (negative or positive) (Jacques, 1996: 67).

There are many companies online publishing their content daily, so people are oversaturated with information that they simply scroll over social media posts without stopping to interact with brands. Marketers know that without user engagement there is no trust in a brand, and thus no long-term relationships.

To improve user engagement, companies invest not only in functionality but also in design for a more engaging user experience. Social media sites offer many functionalities that serve both types of users - companies and individuals, and they both rely heavily on them, especially marketers who are heavily relying on SMA as a marketing intelligence source. Since all companies and brands on social media sites have the same starting point, they need to come up with strategies that will help them stand out from their competition and attract the attention of potential buyers and convert them into regular buyers who are regularly interacting with their brands.

Before creating unique and engaging content, companies need to understand their audience and their motivations. Different motivations, attitudes and needs influence their behavior and inevitably social media marketing success, so marketers' goals are to create content their target audience will like. Design should be appealing to the eye and stand out from the competition. Besides design, marketers invest a lot of time creating a content strategy that will communicate the brand's benefits clearly and in the best way, but also in a target audience's language. They are facing the limitation of characters they can insert in social media posts, so they have to shape the message accordingly. Saying the right thing to the right audience became a must in order to create trust in a brand. There are many statistics on the Internet saying which day in a week and at what time is best to publish on social media. Social media analytics can help marketers to figure out when their target audience is online. Publishing content to the right audience has to 
be at the right time so they can see it. Although 90\% of information transmitted to the brain is visual (Smart Insights, 2020), marketers are struggling to figure out which visual will attract the viewers' attention and increase the number of reactions on posts. These are some of the many factors that may affect user engagement on social media. Good social media strategy that encourages people to react to posts increases user engagement.

The number of post reactions indicates the relevance of a post to the target audience and social media AI helps those posts perform accordingly.

When people react to a post, they automatically start following further reactions and comments, which can engage them in an ongoing conversation on your business Page (Post Reactions, n.d.).

User engagement is a key performance indicator for digital organizations; user growth (e.g., followers, subscribers, etc.) and interactions (e.g., likes, comments, shares, etc.) are common measures of a company's success and indications of user satisfaction (Aldous et al., 2019).

The success of user engagement can be also measured by positive changes in society, behavioral change, personal growth, civic engagement, knowledge transfer, etc. This indicates that user engagement manifests differently within different contexts, that is why there is no widely accepted definition and metrics for user experience.

\section{Methodology}

\subsection{Data collection}

The data used in this study were manually collected from a Facebook business page of a non-profit organization from Bosnia and Herzegovina. 98 posts published in the period from January 2020 until March 2021 were examined. Variables in the dataset were in multiple forms: categorical, discrete, interval, and nominal.

\subsection{Sample}

In this research, Facebook posts of a non-profit organization that awards grants and invests in small businesses were examined. Most of the posts had a purpose to announce an open call for grants and/or small businesses and also to promote the results of those activities. Fewer posts were focused on promoting events the organization organized, as well as, promoting the attendance of the members of the organization on events organized by others.

\subsection{Statistical analysis}

For the purpose of data analysis, the multiple descriptive (central tendency and dispersion statistics) and inferential statistics (Regression, ANOVA, sample t-test) were applied using Excel and SPSS software packages. 


\subsection{Research model}

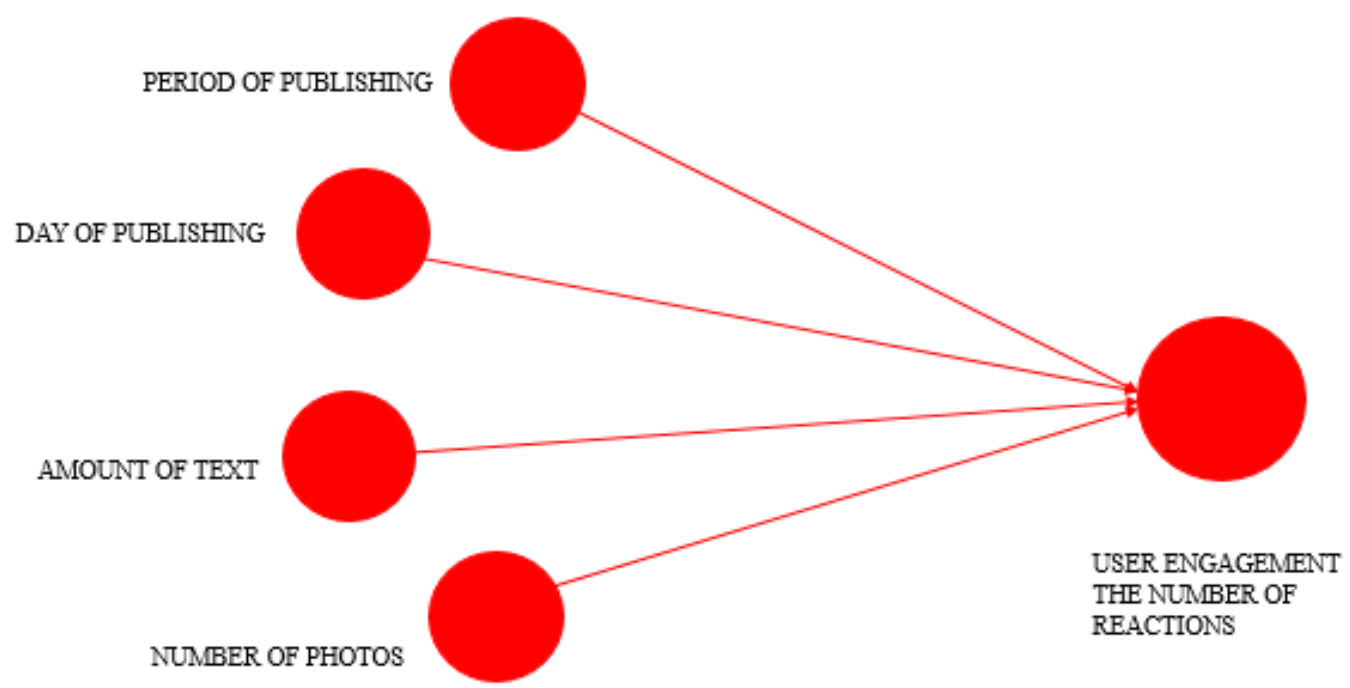

\subsection{Research questions}

- Does the period of publishing posts on Facebook affect the number of reactions?

- Does the day of publishing posts on Facebook affect the number of reactions?

- Does the amount of text of posts on Facebook affect the number of reactions?

- Does the number of media elements (photos) posted on Facebook affect the number of reactions?

\section{Results}

\subsection{Period of publishing posts on Facebook $\rightarrow$ Number of reactions}

In order to find answers to the research question, ANOVA analysis was performed in SPSS, whereby the effects of independent variables on the dependent one(s) were investigated. The results of the analysis are presented in the table below.

Table 1. SPSS outputs: Research question 1

\begin{tabular}{|l|l|l|}
\hline \multicolumn{3}{|c|}{ ANOVA } \\
\hline Number of reactions (like, love, care, haha, wow, sad, angry) \\
\hline & F & Sig. \\
\hline Between Groups & 3.636 & .000 \\
\hline
\end{tabular}

The effects of the period of publishing on Facebook on the number of reactions were investigated. The SPSS output indicated that the effects are statistically significant (Sig.=0.000 which is lower than 0.05). 
If the manager would like to stimulate the number of reactions, he should consider the period of publishing posts on Facebook, as it appears to be a statistically significant independent variable.

\subsection{Day of publishing posts on Facebook $\rightarrow$ Number of reactions}

In order to find answers to the research question, ANOVA analysis was performed in SPSS, whereby the effects of independent variables on the dependent one(s) were investigated. The results of the analysis are presented in the table below.

Table 2. SPSS outputs: Research question 2

\begin{tabular}{|l|l|l|}
\hline \multicolumn{3}{|c|}{ ANOVA } \\
\hline Number of reactions (like, love, care, ha-ha, wow, sad, angry) \\
\hline & F & Sig. \\
\hline Between Groups & 1.433 & .220 \\
\hline
\end{tabular}

The effects of the day of publishing on Facebook on the number of reactions were investigated. The SPSS output indicated that the effects are statistically insignificant (Sig. $=0.220$ which is lower than 0.05).

\subsection{Amount of text $\rightarrow$ Number of reactions}

In order to find answers to the research question, REGRESSION analysis was performed in SPSS, whereby the effects of independent variables on the dependent one(s) were investigated. The results of the analysis are presented in the table below.

Table 3. SPSS outputs: The main research question 3

\begin{tabular}{|c|c|c|c|}
\hline \multicolumn{4}{|l|}{ Coefficients $^{\mathbf{a}}$} \\
\hline \multirow[t]{2}{*}{ Model } & $\begin{array}{l}\text { Standardized } \\
\text { Coefficients }\end{array}$ & \multirow[t]{2}{*}{$\mathrm{t}$} & \multirow[t]{2}{*}{ Sig. } \\
\hline & Beta & & \\
\hline Number of words in a post description & -.020 & -.194 & .846 \\
\hline
\end{tabular}

The effects of the amount of text on the number of reactions were investigated. The SPSS output indicated that the effects are statistically insignificant (Sig. $=0.846$ which is higher than 0.05). Beta is -0.020. If the independent variable (amount of text) increases by 1 unit, the dependent variable decreases by 0.020 .

\subsection{Number of photos in posts on Facebook $\rightarrow$ Number of reactions}

In order to find answers to the research question, REGRESSION analysis was performed in SPSS, whereby the effects of independent variables on the dependent one(s) were investigated. The results of the analysis are presented in the table below. 
E. Mekić \& M. Zerdo-Puljić - Social Media Marketing for User Engagement: Evidence from...

Table 4. SPSS outputs: Research question 4

\begin{tabular}{|c|c|c|c|c|}
\hline \multicolumn{5}{|c|}{ Coefficients $^{\mathrm{a}}$} \\
\hline \multicolumn{2}{|c|}{ Model } & $\begin{array}{l}\text { Standardized } \\
\text { Coefficients }\end{array}$ & $\mathrm{t}$ & Sig. \\
\hline 1 & Media elements (number of photos) & .259 & 2.622 & .010 \\
\hline
\end{tabular}

The effects of the number of photos in posts on Facebook on the number of reactions were investigated. The SPSS output indicated that the effects are statistically significant (Sig.=0.010 which is lower than 0.05). Beta is 0.259. If the independent variable (the number of photos) increases by 1 unit, the dependent variable decreases by 0.259 . It is recommended not to increase the number of photos.

Table 5. Summary of research questions

\begin{tabular}{|l|l|l|l|}
\hline RQ 1 & $\begin{array}{l}\text { Does the period of publishing } \\
\text { posts on Facebook affect the } \\
\text { number of reactions? }\end{array}$ & $\begin{array}{l}\text { Statistically } \\
\text { significant }\end{array}$ \\
\hline RQ 2 & $\begin{array}{l}\text { Does the day of publishing posts } \\
\text { on Facebook affect the number of } \\
\text { reactions? }\end{array}$ & Sig. .220 & $\begin{array}{l}\text { Statistically } \\
\text { insignificant }\end{array}$ \\
\hline RQ 3 & $\begin{array}{l}\text { Does the amount of text of posts on } \\
\text { Facebook affect the number of } \\
\text { reactions? }\end{array}$ & $\begin{array}{l}\text { Sig. .846 } \\
\text { insignificant }\end{array}$ \\
\hline RQ 4 & $\begin{array}{l}\text { Does the number of media } \\
\text { elements (photos) posted on } \\
\text { Facebook affect the number of } \\
\text { reactions? }\end{array}$ & $\begin{array}{l}\text { Statistically } \\
\text { significant }\end{array}$ \\
\hline
\end{tabular}

All the results presented in this section will be further discussed.

\section{Discussion and conclusion}

With 2.85 billion monthly active users, Facebook is the biggest social network in the world (Statista, 2021). There are more than 60 million business pages on Facebook (Kit, 2019). Non-profit organizations use social media sites to increase their user engagement. Although nonprofit organizations in Bosnia and Herzegovina use social media sites, there is poor empirical evidence.

Facebook post engagement is measured through post shares, post reactions, post saves, post comments, post likes, post interactions, 3-seconds video plays, photo views and link clicks (Post Engagement, n.d.). This study investigated which social media factors had an influence on user engagement of the non-profit organization in $\mathrm{BiH}$ - particularly on the number of reactions on Facebook posts - if the period of publishing, the day of publishing, the amount of text and the number of photos in Facebook posts affect the number of post reactions.

When people react to a post, they automatically start following further reactions and comments, which can engage them in an ongoing conversation on your business Page (Post Reactions, n.d.). 
98 posts published in the period from January 2020 until March 2021 were examined and analyzed in SPSS.

The SPSS output indicated that the period of publishing Facebook posts has statistically significant effects (Sig.=0.00o lower than 0.05) on the number of post reactions. If the organization wants to stimulate the number of post reactions, it should consider the period of publishing.

Unlike the period of publishing, the day of publishing posts on Facebook does not have a statistically significant effect on the number of post reactions (Sig.=220 higher than 0.05).

The amount of text in Facebook posts also does not have a statistically significant effect on the number of post reactions (0.846 higher than 0.05).

The number of photos posted in a Facebook post has a statistically significant effect on the number of post reactions (Sig. $=0.010$ which is lower than 0.05). It is recommended not to increase the number of photos in a Facebook post because it may negatively affect the number of reactions.

\section{Acknowledgements}

This research did not receive any specific grant from funding agencies in the public commercial, or not-for-profit sectors.

The authors declare no competing interests.

\section{References}

Aldous, K. K., An, J., \& Jansen, B. J. (2019). View, like, comment, post: Analyzing user engagement by topic at 4 levels across 5 social media platforms for 53 news organizations. Proceedings of the $13^{\text {th }}$ International Conference on Web and Social Media, ICWSM 2019, Icwsm, 47-57.

Arnold, R. A. (2009). Macroeconomics. Cengage Learning.

Barker, M., Barker, D. I., Bormann, N. F., Zahay, D., \& Roberts, M. Lou. (2017). Social media marketing: A strategic approach, $2^{\text {nd }}$ Edition. Cengage Learning.

Chen, S. C., \& Lin, C. P. (2019). Understanding the effect of social media marketing activities: The mediation of social identification, perceived value, and satisfaction. Technological Forecasting and Social Change, 140(November 2018), 22-32. https://doi.org/10.1016/j.techfore.2018.11.025

Chi, H.-H. (2011). Interactive digital advertising vs. virtual brand community. Journal of Interactive Advertising, 12(1), 44-61. https://doi.org/10.1080/15252019.2011.10722190

Clement, J. (2020). Internet users in the world 2020 I Statista. Statista. https://www.statista.com/statistics/617136/digital-population-worldwide/.

Di Gangi, P. M., \& Wasko, M. (2016). Social media engagement theory: Exploring the influence of user engagement on social media usage. Journal of Organizational and End User Computing, 28(2), 53-73. https://doi.org/10.4018/JOEUC.2016040104

Gao, H., Tate, M., Zhang, H., Chen, S., \& Liang, B. (2018). Social media ties strategy in international branding: An application of resource-based theory. Journal of International Marketing, 26(3), 45-69. https://doi.org/10.1509/jim.17.0014 
E. Mekić \& M. Zerdo-Puljić - Social Media Marketing for User Engagement: Evidence from...

Groundswell, J. (2011). Groundswell, expanded and revised edition: Winning in a world transformed by social technologies. Global Media Journal, 5(17), 3-6.

How powerful is visual content in a marketing strategy (2020). Smart Insights. https://www.smartinsights.com/content-management/how-powerful-is-visual-content-in-amarketing-strategy/.

Jacques, R. D. (1996). The Nature of Engagement and Its Role in Hypermedia Evaluation and Design. South Bank University.

Jaakonmäki, R., Müller, O., \& vom Brocke, J. (2017). The impact of content, context, and creator on user engagement in social media marketing. Proceedings of the 5oth Hawaii International Conference on System Sciences (2017), January. https://doi.org/10.24251/hicss.2017.136

Jessica, M (2021). Facebook Engagement: What Is It \& How Do You Measure It. Databox. https://databox.com/facebook-engagement-tips\#head1.1

Kaplan, A. M., \& Haenlein, M. (2010). Users of the world, unite! The challenges and opportunities of social media. Business Horizons, 53(1), 59-68. https://doi.org/10.1016/j.bushor.2009.09.003

Kit, S. (2019). 53 Incredible Facebook Statistics and Facts. Brandwatch. https://www.brandwatch.com/blog/facebook-

statistics/\#: :text=There\%20are\%20over\%2060\%20million,be\%2oreached\%20through\%20 Facebook\%20ads.

Laurel, B. (2013). Computers as Theatre TOC. In Computers as Theatre. https://books.google.com/books?id=kfEEAQAAQBAJ\&pgis=1

Maddy, O. (2021). Mind-blowing LinkedIn statistics and facts. Kinsta. https://kinsta.com/blog/linkedinstatistics/

Naylor, R. W., Lamberton, C. P., \& West, P. M. (2012). Beyond the "like" button: The impact of mere virtual presence on brand evaluations and purchase intentions in social media settings. Journal of Marketing, 76(6), 105-120. https://doi.org/10.1509/jm.11.0105

O'Brien, H., \& Cairns, P. (2016). Why engagement matters: Cross-disciplinary perspectives of user engagement in digital media. In Why Engagement Matters: Cross-Disciplinary Perspectives of User Engagement in Digital Media. https://doi.org/10.1007/978-3-319-27446-1

Post Engagement (n.d.). Facebook for Business. https://www.facebook.com/business/help/735720159834389?locale=en_US.

Post Reactions (n.d.). Facebook for Business. https://www.facebook.com/business/help/118654155244100.

Rapp, A., Beitelspacher, L. S., Grewal, D., \& Hughes, D. E. (2013). Understanding social media effects across seller, retailer, and consumer interactions. Journal of the Academy of Marketing Science, 41(5), 547-566. https://doi.org/10.1007/s11747-013-0326-9

Sining, C., \& Yanxia, Z. (2012). Social media marketing. Life Science Journal, 13(2), 154-160.

Statista. (2020). Most used social media 2020 | Statista. Statista.Com. https://www.statista.com/statistics/272014/global-social-networks-ranked-by-number-ofusers/

Tatnkovska, H. (2020). Number of social media users 2025 | Statista. Statista. https://www.statista.com.remotexs.ntu.edu.sg/statistics/278414/number-of-worldwidesocial-network-users/\%oAhttps://www.statista.com/statistics/278414/number-ofworldwide-social-network-users/.

Yadav, M., \& Rahman, Z. (2017). Measuring consumer perception of social media marketing activities in ecommerce industry: Scale development \& validation. Telematics and Informatics, 34(7), 12941307. https://doi.org/10.1016/j.tele.2017.06.001 
Zeng, D., Chen, H., Lusch, R., \& Li, S. H. (2010). Social media analytics and intelligence. IEEE Intelligent Systems, 25(6), 13-16. https://doi.org/10.1109/MIS.2010.151

Hristina, T. (2021). Number of monthly active Facebook users worldwide as of 1st quarter 2021. Statista. https://www.statista.com/statistics/264810/number-of-monthly-active-facebook-usersworldwide/. 
E. Mekić \& M. Zerdo-Puljić - Social Media Marketing for User Engagement: Evidence from...

C $O$ A $\mathbf{s}$ 